\title{
The effects of smartphone width on touch performance
}

\author{
Seul Chan Lee (seulchan@yonsei.ac.kr) ${ }^{1}$, Yong Gu Ji (yongguji@yonsei.ac.kr) ${ }^{1}$ \\ ${ }^{1}$ Department of Industrial Engineering, Yonsei University, Seoul, 120-749
}

\begin{abstract}
The aim of the study is to test the effects of smartphone width on touch performances in order to investigate the appropriate size of smartphone for one-handed interaction. We used four different width level for the experiment, which were $67 \mathrm{~mm}$, $70 \mathrm{~mm}, 72 \mathrm{~mm}$, and $74 \mathrm{~mm}$. Participants were asked to perform tapping task. We measured two touch performances, success rate and task completion time. The success rate of $67 \mathrm{~mm}$ device was higher than that of other devices. We confirmed that this results come from the poor performances at marginal screen area. However, task completion time of $67 \mathrm{~mm}$ device was unexpectedly poor than that of other devices.
\end{abstract}

Keywords: smartphone form factors, width, one-handed interaction. Touch performance,

\section{Introduction}

The smartphone becomes most important devices for the information and communication activities. As the population of smartphone increases, many people want to perform more various tasks using smartphones. Accordingly, the smartphone makers adopt a strategy for increasing the size of smartphone screen (Chiang, et al., 2013).

However, the size of device increases according to increasing size of smartphone screen. In terms of ergonomic point of view, increasing size of device leads to deteriorate the touch performances on the screen. Particularly, considering many people usually use the smartphone based on one-handed interaction, it is expected that it is hard to perform touch behaviors on edge area of screen.

Findings of previous works revealed that increasing size of smartphone display make people feel tired because of bad grip comfort (Kietrys et al., 2015; Pereira et al., 2013). Furthermore, usability of smartphone is also deteriorated because of smartphone size (Xiong \& Muraki, 2016). Therefore, we aimed at investigating the effects of device size of smartphone on touch performances.

\section{Method}

We conducted an experiment to determine the effects of device size on touch performances. The experimental task was to touch the target icon on the entire screen.

Participants A total of sixty-six participants (male: 34, female: 32 ) were included for the experiment. The age of participants was ranged from 19 to 39 years (mean: 29.1 years, sd: 4.81). All participants were right-handed or ambidextrous. We measured the sizes of hand. The average hand length was $192.31 \mathrm{~mm}$ for men and $180.97 \mathrm{~mm}$ for women, palm width was $91.66 \mathrm{~mm}$ for men and $77.10 \mathrm{~mm}$ for women, and thumb length was $65.77 \mathrm{~mm}$ for men and $59.22 \mathrm{~mm}$ for women.

Tasks To test one-handed interaction with smartphones, we require participants to perform a tapping task. This task paradigm was widely used in previous studies (Perry and Hourcade, 2008). Participants were asked to touch the target icons as fast as and correctly as possible. If participants tapped the target exactly, then next target was presented directly. The task difficulty was controlled by varying the size of targets, which were $5 \mathrm{~mm}$ and $10 \mathrm{~mm}$.

Experimental variables We selected the smartphone width as a representative of device size. Therefore, the independent variable of the experiment is the smartphone width. The range of independent variable is 
from $67 \mathrm{~mm}$ to $74 \mathrm{~mm}$, which include the size of most premium smartphones. We divided independent variable into four levels, $67 \mathrm{~mm}, 70 \mathrm{~mm}, 72 \mathrm{~mm}$, and $74 \mathrm{~mm}$.

We collected two performance measures as dependent variables, success rate and task completion time. The success rate was calculated by the number of success divided by total trials. Only successful trials were included in calculating task completion time.

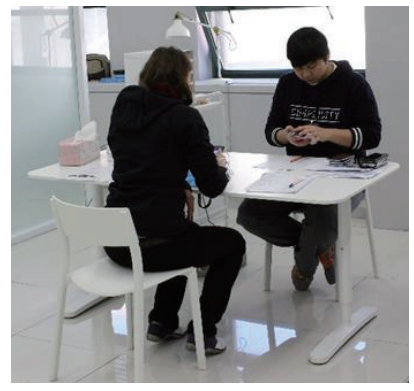

Figure 1. Experimental environment

\section{Results}

The average success rates were $80.2 \%, 77.4 \%, 77.1 \%$, and $77.9 \%$ for each device respectively (Figure 1 ). We conducted a two-way analysis of variance on success rate with width and target size. The results showed that there were significant main effects, but the interaction effects was not significant (width: $\mathrm{df}=3, \mathrm{~F}=4.26, \mathrm{p}<0.01$; task difficulty: $\mathrm{df}=1, \mathrm{~F}=14.51 ; \mathrm{p}<0.01$, width $\times$ task difficulty: $\mathrm{df}=3, \mathrm{~F}=1.94, \mathrm{p}=0.122$ ).

In order to scrutinize the success rate, we analyzed the success rate based on the distance from basic thumb position (Figure 2). We found that the success rate decreases as the distance from basic position increases. Particularly, this effects were clear for the large device, meaning that the deterioration in performance was caused by difficulties performing task at marginal area of screen.

The task completion time was $541.9 \mathrm{~ms}$, $494.3 \mathrm{~ms}$, $502.1 \mathrm{~ms}, 508.2 \mathrm{~ms}$ respectively (Figure 3 ). We also carried out a two-way analysis of variance on task completion time including width and target size. The results showed that there were significant main and interaction effects (width: $\mathrm{df}=3, \mathrm{~F}=82.306, \mathrm{p}<0.01 ;$ task difficulty: $\mathrm{df}=1, \mathrm{~F}=$ 8424.301, $\mathrm{p}<0.01$; width $\times$ task difficulty: $\mathrm{df}=3, \mathrm{~F}=6.47$, $\mathrm{p}<0.01)$.

We also analyzed the task completion time based on the distance from the basic thumb position. The results showed that task completion time increases as target was positioned at marginal area.

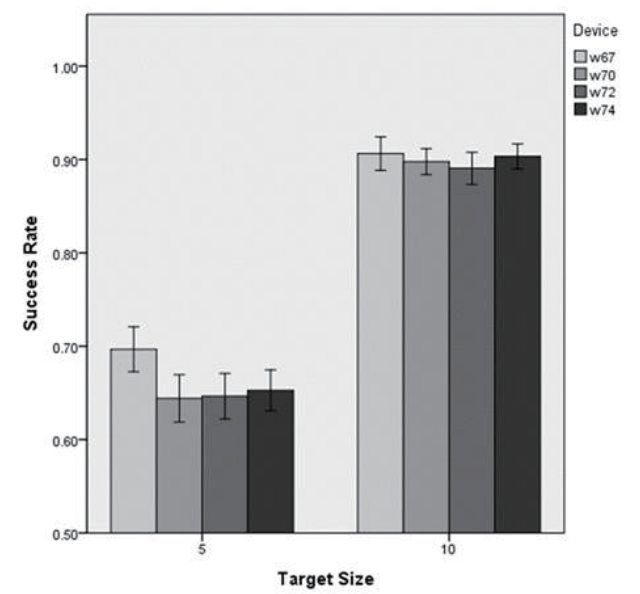

Figure 2. The success rate of devices according to target size
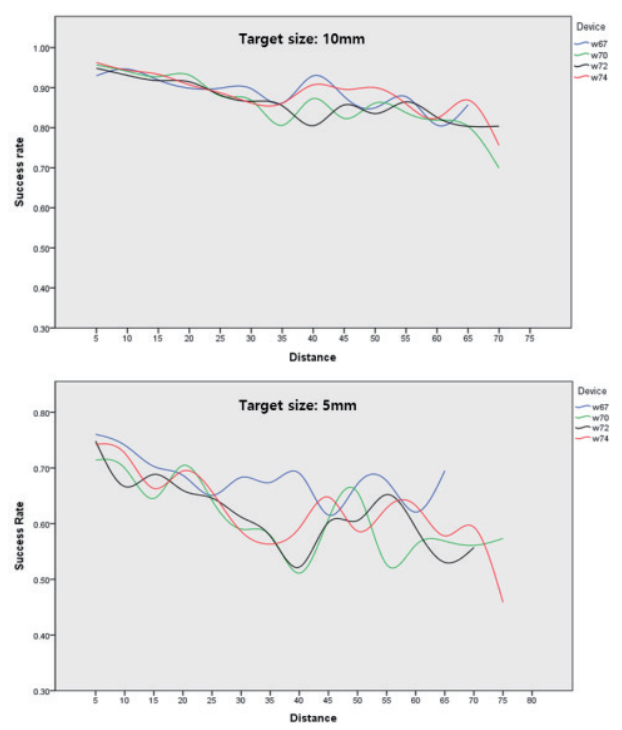

Figure 3. The success rate according to distance from basic position.

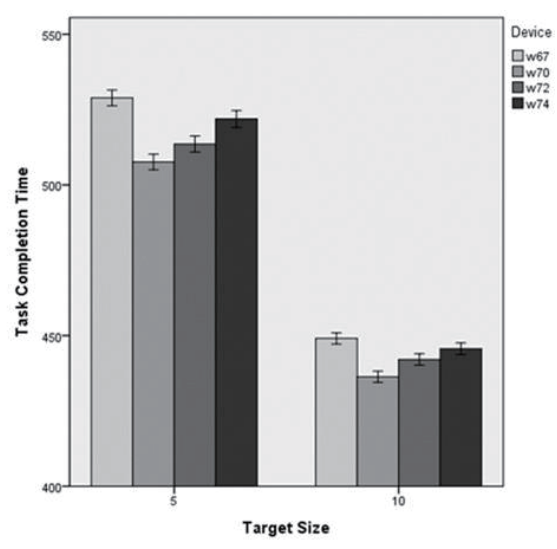

Figure 4. The task completion time of devices according to target size 

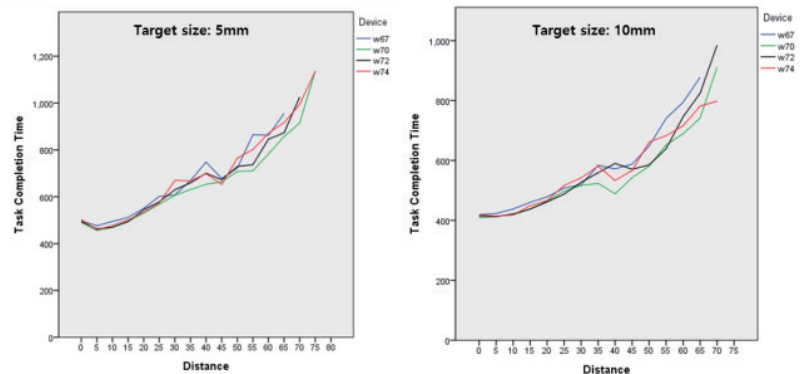

Figure 5. The task completion time according to

\section{Discussion \& Conclusion}

In this study, we tested the effects of smartphone width on touch performances to investigate the appropriate size of smartphone for one-handed interaction.

The task difficulty was controlled by providing two different target sizes to test the appropriateness of smartphone width. Although the results showed that there were no differences of success rate between devices in $10 \mathrm{~mm}$ target condition, the success rate was better by decreasing smartphone width in $5 \mathrm{~mm}$ target condition. In particular, the success rate of $67 \mathrm{~mm}$ device was higher than that of other devices and the results of rest devices were similar. This result is in line with findings of previous works (Colle and Hiszem, 2004; Hwangbo et al., 2013; Parhi et al., 2006, September)

We expected that the results of task completion time were similar with those of success rate. However, the task completion time of $67 \mathrm{~mm}$ devices was poor regardless of task difficulties. This indicates that although it is easy to tap the target when the size of device decreases below the specific level, it is difficulty tapping efficiently. However, it is hard to conclude based on our results, further research should be conducted.

\section{Acknowledgements}

This work is financially supported by Korea Ministry of Land, Infrastructure and Transport(MOLIT) as 「U-City Master and Doctor Course Grant Program.

\section{References}

Chiang, Z. H., Wen, C. C., Chen, A. C., \& Hou, C. Y. (2013, July). An analysis of smartphone size regarding operating performance. In International Conference on Human Interface and the Management of Information (pp. 363-372). Springer Berlin Heidelberg.

Colle, H. A., \& Hiszem, K. J. (2004). Standing at a kiosk: Effects of key size and spacing on touch screen numeric keypad performance and user preference. Ergonomics, 47(13), 1406-1423.

Hwangbo, H., Yoon, S. H., Jin, B. S., Han, Y. S., \& Ji, Y. G. (2013). A study of pointing performance of elderly users on smartphones International Journal of Human-Computer Interaction, 29(9), 604-618.

Kietrys, D. M., Gerg, M. J., Dropkin, J., \& Gold, J. E. (2015). Mobile input device type, texting style and screen size influence upper extremity and trapezius muscle activity, and cervical posture while texting. Applied ergonomics, 50, 98-104.

Parhi, P., Karlson, A. K., \& Bederson, B. B. (2006, September) Target size study for one-handed thumb use on small touchscreen devices. In Proceedings of the 8th conference on Human-computer interaction with mobile devices and services (pp. 203-210). ACM.

Pereira, A., Miller, T., Huang, Y. M., Odell, D., \& Rempel, D. (2013) Holding a tablet computer with one hand: effect of tablet design features on biomechanics and subjective usability among users with small hands. Ergonomics, 56(9), 1363-1375.

Perry, K. B., \& Hourcade, J. P. (2008, May). Evaluating one handed thumb tapping on mobile touchscreen devices. In Proceedings of graphics interface 2008 (pp. 57-64). Canadian Information Processing Society.

Xiong, J., \& Muraki, S. (2016). Effects of age, thumb length and screen size on thumb movement coverage on smartphone touchscreens. International Journal of Industrial Ergonomics, $53,140-148$. 